\title{
Influence of Wrinkles in Sheet Metal Forming on Ultrasonic Reflection Characteristics of Angled Beam
}

\author{
Yuji Segawa, ${ }^{1 *}$ Shinya Watanabe, ${ }^{1}$ Yasuo Marumo, ${ }^{2}$ \\ Tomohiro Nonaka, ${ }^{3}$ and Yutaka Sakata ${ }^{4}$ \\ ${ }^{1}$ Department of Mechanical Engineering, National Institute of Technology (KOSEN), Miyakonojo College, \\ 473-1 Yoshio-cho, Miyakonojo, Miyazaki 885-8567, Japan \\ ${ }^{2}$ Faculty of Advanced Science and Technology, Kumamoto University, \\ 2-39-1 Kurokami, Chuo-ku, Kumamoto 860-8555, Japan \\ ${ }^{3}$ NONAKA 3D Laboratory, \\ 1-6-29 Hikino, Yahatanishi-ku, Kitakyushu, Fukuoka 806-0067, Japan \\ ${ }^{4}$ Department of Integrated System Engineering, Nishinippon Institute of Technology, \\ 1-11 Aratsu, Kanda-machi, Miyako-gun, Fukuoka 800-0394, Japan
}

(Received March 20, 2019; accepted September 2, 2019)

Keywords: sheet metal forming, wrinkle, defect, detect, sensor, in-process, ultrasonic wave, angled beam

In this paper, the relationships between wrinkles in sheet press forming and the ultrasonic reflection characteristics of an angled beam are shown. An angled probe was used assuming a case in which a vertical probe cannot be placed directly above defects. The wrinkles were evaluated using an apparatus that reproduced the die-workpiece contact situation of press forming. Model specimens used in the experiments had trapezoidal wrinkles similar to the wrinkle shape in press forming. The workpiece was sandwiched by dies in the apparatus. The apparatus was connected to an ultrasonic flaw detector. The relationship between the wrinkle shape and the irradiation position of ultrasonic waves was accurately obtained using the apparatus. Wrinkling was detected from the change in reflection intensity, i.e., the maximum amplitude of reflected waves. The reflection intensity varied with the wrinkle shape for a single wrinkle or periodic wrinkle with a wrinkle wavelength of $8 \mathrm{~mm}$ or more. This tendency was also observed for a vertical probe. The wrinkle evaluation using the angled probe was as effective as that using a vertical probe.

\section{Introduction}

In the field of sheet metal forming, technological developments enabling reduction of inspection cost, monitoring of processing conditions, and prediction of defect occurrence have been actively pursued utilizing the Internet of Things (IoT). For example, information obtained from sensors attached to a machine tool is analyzed and utilized.

A number of acoustic emission (AE) sensors attached to the wall surface of a die can identify the contact and friction states of a workpiece and the die by the arrival time of the AE signal emitted from the friction source of the die and the workpiece during deep drawing. ${ }^{(1)}$ In ring compression, upset forging, and cross-joint forging processes, the occurrence of cracks *Corresponding author: e-mail: y_segawa@cc.miyakonojo-nct.ac.jp https://doi.org/10.18494/SAM.2019.2376 
can be detected from the change of the $\mathrm{AE}$ signal. ${ }^{(2)}$ In hot forging, electric conductivity was used to observe forging processes. The electric circuit included an injection nozzle and an electrode, which was installed in the cooling system, in contact with the injected lubricant. The high quality and process stability of forging was maintained by monitoring the circuit voltage fluctuation. ${ }^{(3)}$ A load sensor and transmission-type fiber-laser sensors detected the scrapjumping in pierce processing. ${ }^{(4)}$ Several methods were also developed for deep drawing. For instance, the amount of retraction of thin sheets was measured using mutual inductance and the loads acting on thin sheets were measured using piezo resistance. ${ }^{(5,6)}$ A closed-loop circuit constituted of various sensors attached to the die could reveal the relationships among the following quantities: punch load, punch stroke, pressure in the cylinder, the die-blank holder distance, and blank holder force. ${ }^{(7)}$ Using the above information, the blank holder force was adjusted $^{(8)}$ and the die was segmented ${ }^{(9)}$ consequently, the formation of wrinkles was prevented. A borescope incorporating a compact CCD camera was installed in the tool cavity and was used to measure the deformation behavior of the sheet during press forming and tool deflection. ${ }^{(10)}$ Moreover, the methods of detecting defects by bispectral analysis ${ }^{(11)}$ of acceleration signals and wavelet transformation $^{(12)}$ of distortion signals, and the method of detecting burrs in punching from the change in vibration signals during processing ${ }^{(13)}$ have been reported.

The application of ultrasonic measurement to in-process evaluation was also attempted. The change in the tool-workpiece contact state during forging was evaluated by continuously measuring the ultrasonic reflection intensity on the contact surface. ${ }^{(14)}$ Furthermore, in the ring compression test of aluminum under lubrication conditions, the contact pressure and the friction shear stress on the tool-workpiece contact interface were obtained through continuous measurement of the ring outer diameter and ultrasonic measurement of the contact interface. ${ }^{(15,16)}$ The AE sensor measures elastic waves propagating in the machine and tool. The detection area of the AE sensor is wide. However, the information obtained by the AE sensor contains noise, and signal processing is required to evaluate the information. The evaluation of some defects is not easy because the AE sensor seems to be unclear regarding the target evaluated. In contrast, the reflection of ultrasonic waves can directly clear the contact state between the tool and the workpiece. Although the ultrasonic method has a narrower inspection range than the AE method, it is effective for evaluating some defects including wrinkles. In the investigation of the use of a flat die and a V-shaped die, it was revealed that the material and thickness of pressed products affected the ultrasonic reflection and transmission characteristics. ${ }^{(17)}$ The ultrasonic probe embedded in the die detected the change in the reflection intensity owing to the difference in the contact ratio between the die and the workpiece. Thus, this method is applicable to the detection of wrinkles generated during press forming. ${ }^{(18)}$

The authors performed the ultrasonic measurement using the vertical probe in deep drawing and showed a method of evaluating wrinkle defects during processing on the basis of the change in the maximum amplitude of reflected waves. ${ }^{(19)}$ The frequency characteristics of the reflected waves were also used to evaluate wrinkles. ${ }^{(20)}$ The experiments on the use of wrinkle model specimens simulating actual wrinkles revealed that the ultrasonic reflection characteristics were affected by the wrinkle wavelength, ultrasonic effective probe diameter, and ultrasonic irradiation diameter. ${ }^{(21-23)}$ 
In this study, to verify the effectiveness of the angled beam technique for wrinkle evaluation, ultrasonic experiments were conducted using angled probes and the evaluation apparatus presented in a previous paper. $^{(24)}$ In detecting wrinkles, the vertical probe should be placed just above the location where a defect is predicted to occur. However, the angled probe can be placed at an angled position to the defect. In other words, the angled probe can be placed at any position as long as the ultrasonic waves directly reach the target. The ultrasonic detection method can be applied to various tools and dies by coupling the vertical probe and angled angle probe. In addition, the detection accuracy can be improved by the coupling.

\section{Experimental Conditions and Procedures}

\subsection{Principle of wrinkle evaluation using ultrasonic waves}

Ultrasonic waves simultaneously reflect and transmit at the interface when the acoustic impedances (sound velocity $\times$ density) of two contact media are different. The wrinkles in press forming can be evaluated using the above property. Figure 1 shows the relationship between the reflection of the ultrasonic waves irradiated from the vertical probe and the die-workpiece contact state. The maximum amplitude of the reflected wave is defined as the reflection intensity $I$. As shown in Fig. 1(a), the reflection intensity is $I_{0}$ when the upper die is not in contact with the workpiece. As shown in Figs. 1(b) and 1(c), the reflection intensity changes to $I_{1}$ and $I_{2}$ depending on the occurrence state of wrinkles. The reflection intensity is $I_{3}$ in the no-wrinkle state shown in Fig. 1(d). The amplitude order of these reflection intensities is $I_{0}>I_{1}>I_{2}>I_{3}$. In this way, the reflection characteristic of the ultrasonic waves depends on the die-workpiece contact state, which is changed by the wrinkling. In this study, the relative reflection intensity, $I / I_{0}$, was used as an index of wrinkle evaluation.

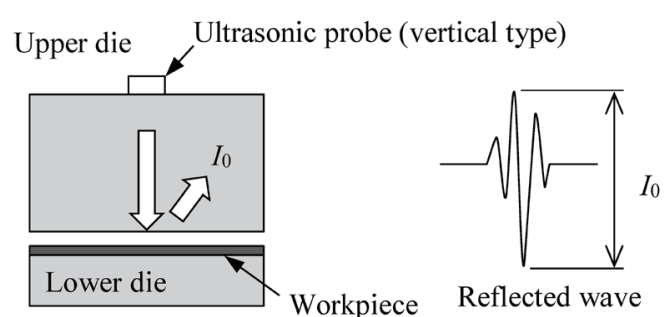

(a)
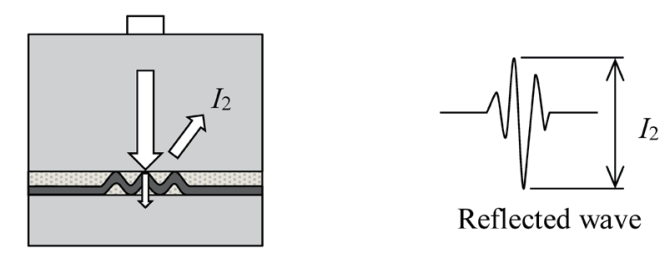

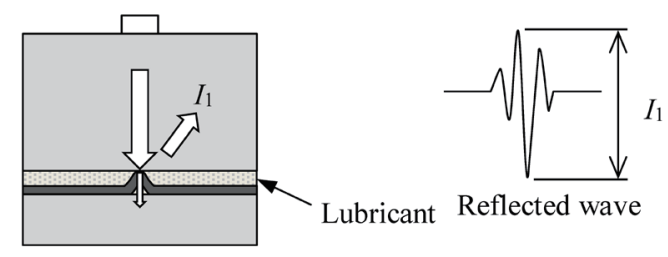

(b)

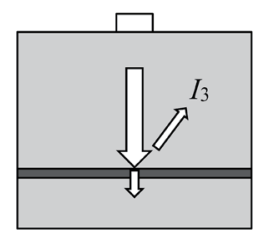

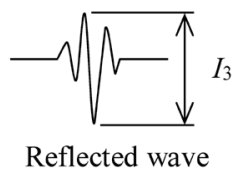

(d)

Fig. 1. Contact states of dies and ultrasonic reflection characteristic $\left(I_{0}>I_{1}>I_{2}>I_{3}\right)$ : (a) contact with air, (b) contact with one wrinkle, (c) contact with wrinkles, and (d) contact without wrinkles. 


\subsection{Experimental procedures}

Figure 2 shows the evaluation apparatus. This experimental apparatus was improved for the angled probe on the basis of the structure of the evaluation apparatus for the vertical probe. ${ }^{(24)}$ The apparatus is composed of four parts: the probe-fixing parts, the upper die, the middle die, and the lower die [Fig. 2(a)]. The probe-fixing parts not only fix the position of the probe but also keep the probe-die contact state constant. In the convex area of the upper die, the distance from its upper surface to its lower surface is $20 \mathrm{~mm}$. The middle die is made of acrylic material so that the die-workpiece contact state could be visually confirmed after setting the workpiece in the experimental apparatus. The other parts are made of JIS-S50C steel. The model specimens with a trapezoidal geometry simulated wrinkles occurring in press forming. They were made of JIS-A1050 aluminum and fabricated by wire electric discharge machining. In this study, the model specimens with a periodic trapezoidal geometry, i.e., multiple wrinkles, and with a single trapezoidal geometry, i.e., a single wrinkle, were used in the experiments. Figure 3 shows the parameters of wrinkle shape: contact width $c_{w}$, wrinkle wavelength $\lambda_{w}$,

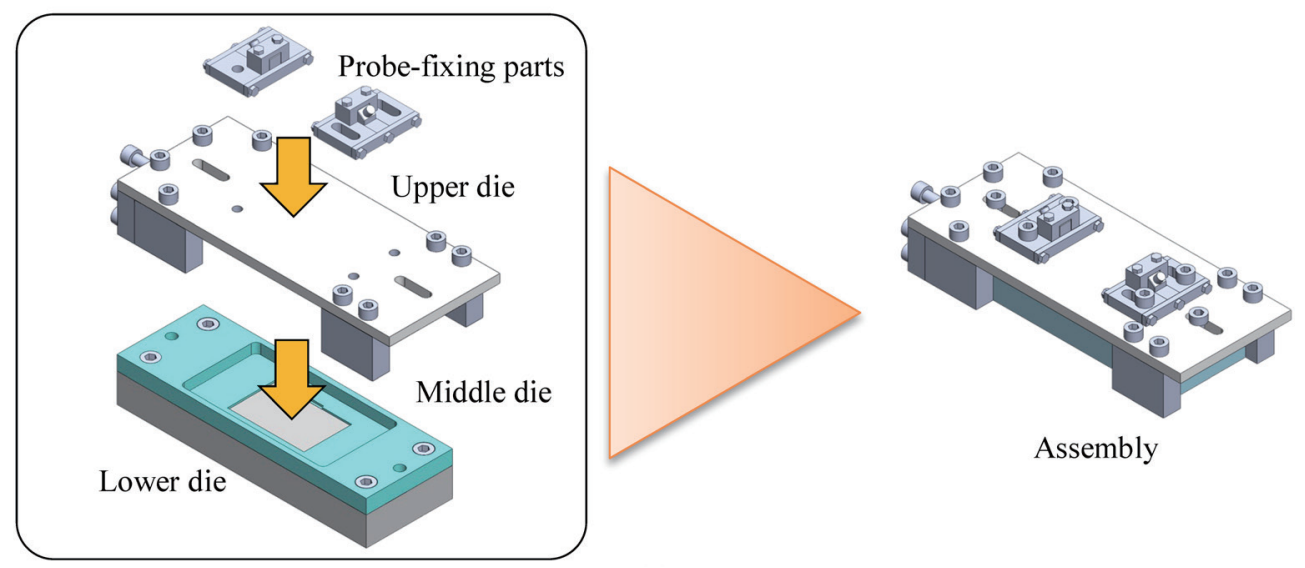

(a)

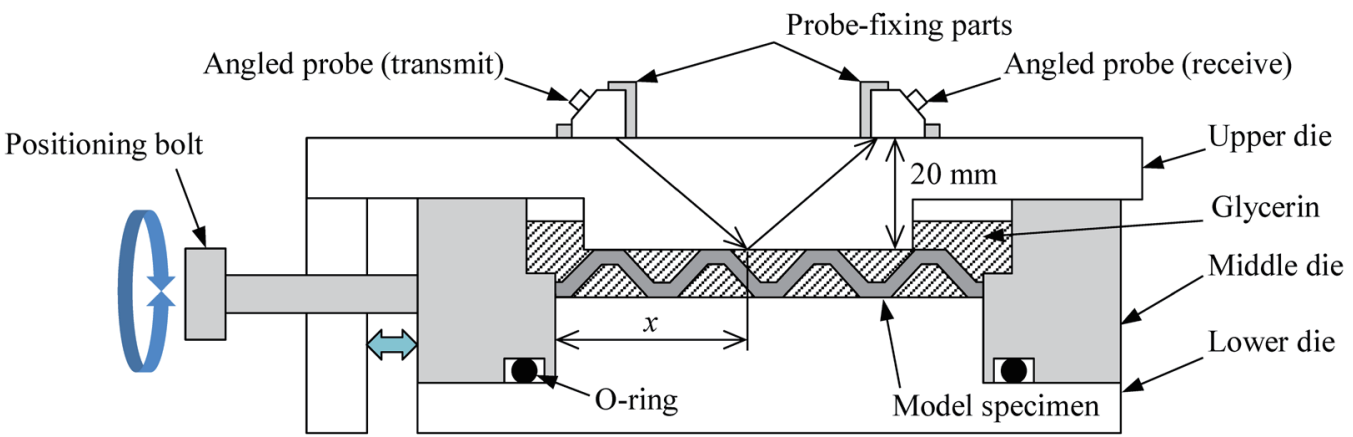

(b)

Fig. 2. (Color online) Schematic of apparatus for evaluation by angled beam technique.

(a) Apparatus configuration and details of parts and (b) measurement principle and mechanism of apparatus. 


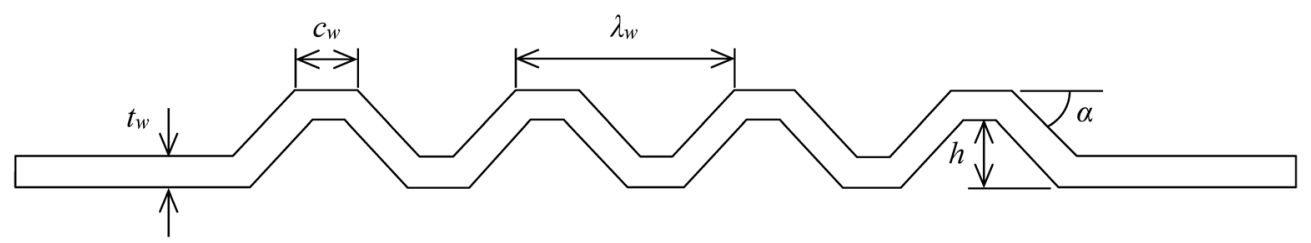

Fig. 3. Shape parameters of model specimen. Contact width $c_{w}$, wrinkle wavelength $\lambda_{w}$, wrinkle slope angle $\alpha$, thickness $t_{w}$, and wrinkle height $h$.

wrinkle slope angle $\alpha$, thickness $t_{w}$, and wrinkle height $h . c_{w}, t_{w}$, and $h$ are all $1 \mathrm{~mm}$ in this study. $\lambda_{w}$ is 4,8 , and $12 \mathrm{~mm}$ in the model specimens of the periodic wrinkle. $\alpha$ of the single wrinkle is the same as that of the periodic wrinkles with $\lambda_{w}=4 \mathrm{~mm}$. The gaps between the wrinkle model specimen and the die were filled with glycerin so that no air enters. The O-ring prevents glycerin from leaking through the gap between the middle and lower dies. The middle and lower dies are moved with high precision in the horizontal direction, as shown in Fig. 2(b), by turning the positioning bolt. The surfaces where the dies come in contact with the specimen were finished by grinding and have appropriate roughness.

Figure 4 shows the ultrasonic measurement equipment. The ultrasonic flaw detector EPOCH1000i made by OLYMPUS was used. For the angled probes, standard angled probes $5 \mathrm{C} 10 \times 10 \mathrm{~A} 70$ made by KGK were used for both the transmitting and receiving sides (frequency $f=5 \mathrm{MHz}$, refraction angle of $70^{\circ}$ ). In this probe, ultrasonic waves propagate as longitudinal waves in the wedge of the probe. Once the ultrasonic waves penetrate into the die, they are converted into transverse waves, which propagate in the die.

The ultrasonic reflection characteristics were investigated by irradiating ultrasonic waves onto various model specimens. In the experiments, the ultrasonic irradiation position $x$ was changed. $x$ is the distance from the center position of the ultrasonic waves reaching the lower surface of the upper die to the end of the workpiece, as shown in Fig. 2(b). The reflection intensity was measured at 20 points within wrinkle waves, i.e., double wrinkle wavelength. The measurement was repeated three times and their mean value was calculated.

\section{Results and Discussion}

\subsection{Influence of wrinkle shape and irradiation position}

Figure 5 shows the variation in the ultrasonic reflection intensity with the ultrasonic irradiation position $x$. The model specimens with periodic trapezoidal wrinkles (Wrinkles), with a single trapezoidal wrinkle (Wrinkle), and with no wrinkles (No wrinkle) were used in the experiments. The wrinkle shapes are arranged in the figures in accordance with $x$ so that the relationship between the wrinkle shape and the irradiation position can be understood. In all the figures, $I / I_{0}$ varied with $x$. Except for the wrinkles with $\lambda_{w}=4 \mathrm{~mm}$ [Fig. 5(c)], the tendency of their variation was similar to the experimental results obtained with the vertical 


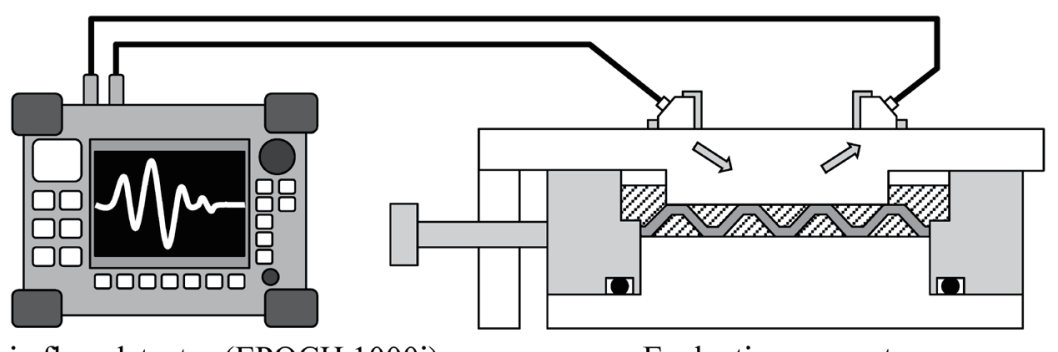

Ultrasonic flaw detector (EPOCH 1000i)

Evaluation apparatus

Fig. 4. Measurement equipment used in this study.
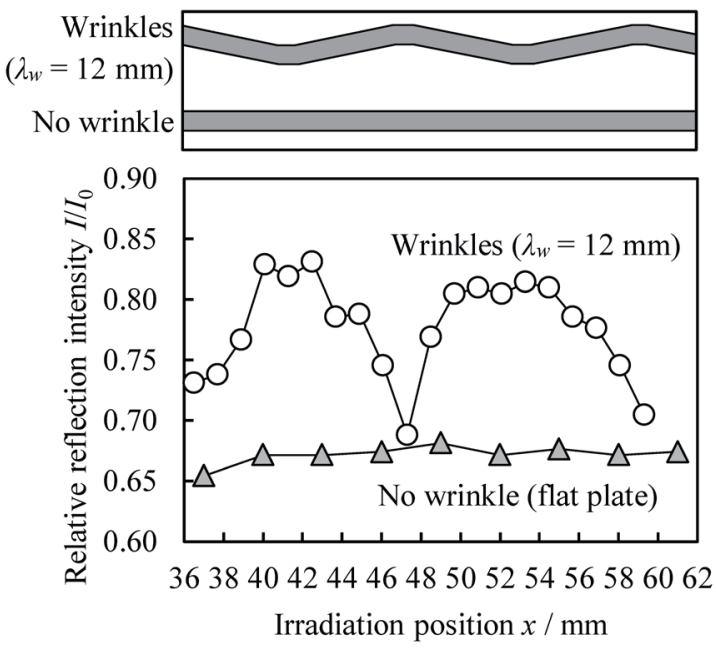

(a)
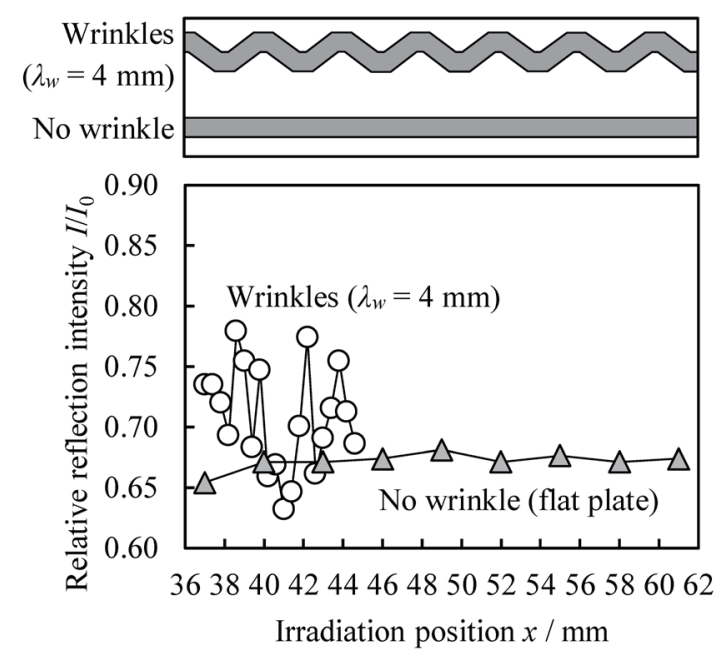

(c)
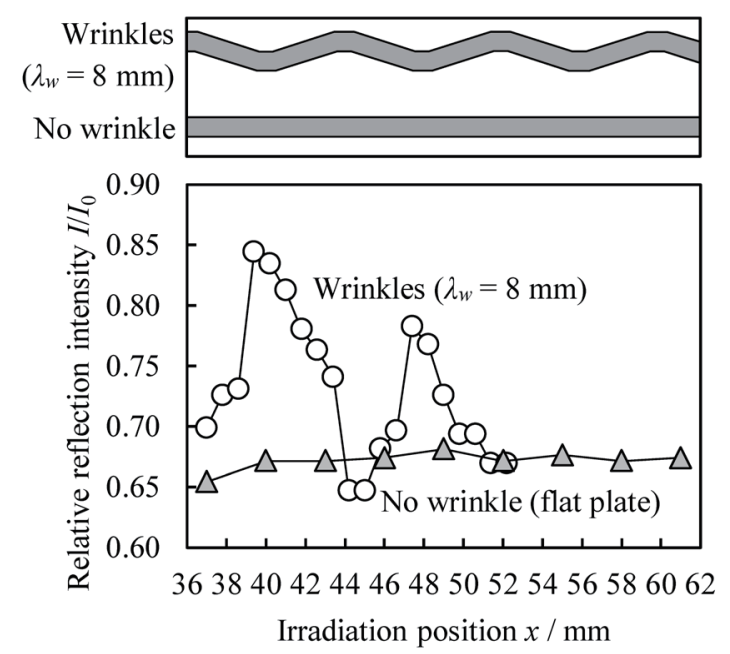

(b)
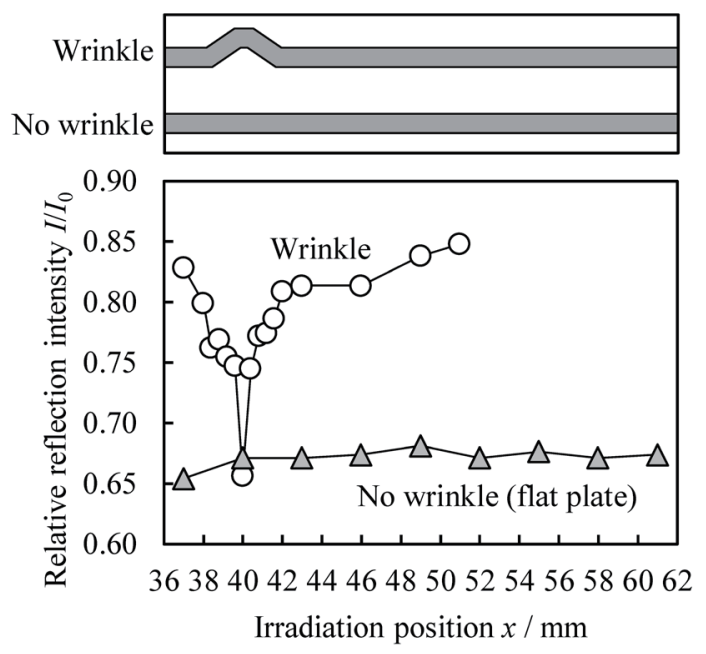

(d)

Fig. 5. Relationship between irradiation position of ultrasonic waves and $I / I_{0}\left(c_{w}, t_{w}, h=1 \mathrm{~mm}\right)$. Wrinkles with (a) $\lambda_{w}=12 \mathrm{~mm}$, (b) $\lambda_{w}=8 \mathrm{~mm}$, and (c) $\lambda_{w}=4 \mathrm{~mm}$, and (d) single wrinkle. 
probe. ${ }^{(22)}$ It was found that the evaluation method with the angled beam technique captured the change in the contact state within the irradiation region of ultrasonic waves. Even for the single wrinkle, $I / I_{0}$ varied with $x$ and the change in the contact state was detected.

For the periodic wrinkle with $\lambda_{w}=4 \mathrm{~mm}$, i.e., a short wrinkle interval, the results obtained using the angled probe were different from those obtained using the vertical probe. It can be reasoned that the difference could be caused by the change in the ultrasonic irradiation diameter owing to the oblique transmission of ultrasonic waves.

\subsection{Change in reflection intensity from convex portion}

Figure 6 shows the variation in the increment in $I / I_{0}, \Delta I / I_{0}$, with the movement of the irradiation position, $\Delta x$, for the single wrinkle and the periodic wrinkles with $\lambda_{w}=8$ and $12 \mathrm{~mm}$. $\Delta x$ is the amount of movement of the irradiation position with reference to the center position of the die-workpiece contact surface. The ranges of $x$ are from 47 to $53 \mathrm{~mm}$ for the periodic wrinkle with $\lambda_{w}=12 \mathrm{~mm}$, from 44.2 to $49.8 \mathrm{~mm}$ for the periodic wrinkle with $\lambda_{w}=8 \mathrm{~mm}$, and from 40 to $46 \mathrm{~mm}$ for the single wrinkle. The relationships between $\Delta x$ and the wrinkle shape are also illustrated in Fig. 6(a). The slope of $\Delta I / I_{0}$ for the single wrinkle is greater than that for the periodic wrinkles because the die-workpiece contact surface in wrinkles other than the reference wrinkle could affect $I / I_{0}$.

\subsection{Relationship between contact state and reflection characteristics}

Figure 7 shows the relationship between $I / I_{0}$ and the contact state of the lower surface of the upper die. Values of $I / I_{0}$ are average ones. Convex indicates average measured values of convex areas in Wrinkle and Wrinkles. The measured values for periodic wrinkles with $\lambda_{w}=4 \mathrm{~mm}$ were excluded. The angled probe detected the difference in the contact state from the change

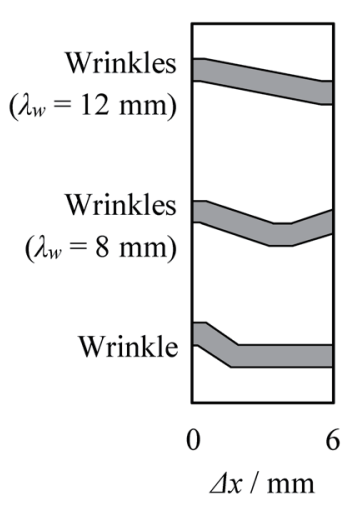

(a)

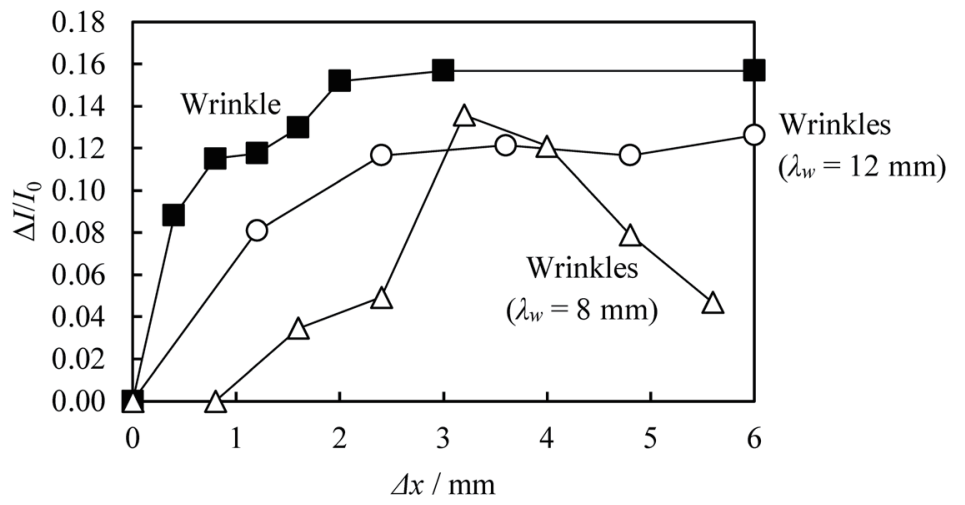

(b)

Fig. 6. Variation of $\Delta I / I_{0}$ from contact region between die and specimen. (a) Relationship between wrinkle shape and $\Delta x$. (b) Relationship between $\Delta I / I_{0}$ and $\Delta x$. 


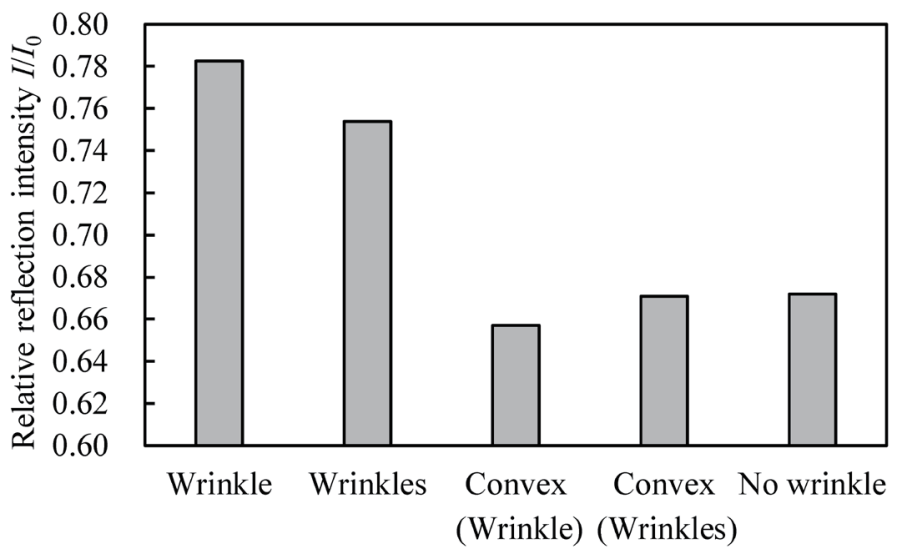

Fig. 7. Relationship between contact state in lower surface of upper die and $I / I_{0}$. Wrinkles and Convex (Wrinkles) show data of two specimens $\left(\lambda_{w}=8\right.$ and $\left.12 \mathrm{~mm}\right)$.

in $I / I_{0}$ depending on the presence or absence of wrinkles. However, $I / I_{0}$ for the convex area of wrinkles was roughly the same as that for no wrinkle. The reason for this may be related to the irradiation position and propagation distance of ultrasonic waves. In order to obtain information on the contact surface and the glycerin around the convex area, the propagation distance and the irradiation position should be adjusted.

\section{Conclusions}

The evaluation of wrinkles by the angled beam technique was examined. The following conclusions were obtained.

1. The angled probe is effective for evaluating the wrinkles using the relative reflection intensity because it captures the change in relative reflection intensity owing to the wrinkling. Nevertheless, it is difficult to use for evaluating the convex part of wrinkles and the continuous wrinkles with small wrinkle wavelengths.

2. Except for wrinkles with small wrinkle wavelengths, the reflection characteristics of the angled beam, i.e., the angled probe, changed depending on the irradiation position of the ultrasonic waves, similar to the vertical probe. However, the angled probe seems to have low sensitivity due to the longer ultrasonic propagation distance than the vertical probe. A detailed comparison between the angled and vertical probes regarding their sensitivity and $N / S$ ratio will be investigated in the near future. In addition, the ultrasonic detection coupling the vertical and angled probes will be examined.

\section{Acknowledgments}

This study was partly supported by a Grant on the Technology of Plasticity for Young Researchers. 


\section{References}

1 M. Yang, K. Manabe, K. Hayashi, M. Miyazaki, and N. Aikawa: J. Mater. Process. Tech. 139 (2003) 368. https://doi.org/10.1016/S0924-0136(03)00533-8

2 B. A. Behrens, A. Bouguecha, C. Buse, K. Wölki, and A. Santangelo: Arch. Civ. Mech. Eng. 16 (2016) 724. https://doi.org/10.1016/j.acme.2016.04.012

3 B. A. Behrens, C. Frischkorn, and I. Lüken: Prod. Eng. 6 (2012) 439. https://doi.org/10.1007/s11740-012-03964

4 T. Nonaka, Y. Sakata, Y. Marumo, Y. Okinishi, T. Horinouchi, I. Ogawa, and S. Watanabe: Appl. Mech. Mater. 182-183 (2012) 472. https://doi.org/10.4028/www.scientific.net/AMM.182-183.472

5 N. Mahayotsanun, S. Sah, J. Cao, M. Peshkin, R. X. Gao, and C. T. Wang: Int. J. Mach. Tool. Manu. 49 (2009) 634. https://doi.org/10.1016/j.ijmachtools.2009.01.009

6 S. Sah, N. Mahayotsanun, M. Peshkin, J. Cao, and R. X. Gao: J. Manuf. Sci. E.-T. ASME 138 (2016) 091005. https://doi.org/10.1115/1.4033039

7 M. Traversin and R. Kergen: J. Mater. Process. Tech. 50 (1995) 306. https://doi.org/10.1016/09240136(94)01389-I

8 S. W. Lo and T. C. Yang: Int. J. Adv. Manuf. Tech. 24 (2004) 553. https://doi.org/10.1007/s00170-003-1711-1

9 K. Siegert, M. Ziegler, and S. Wagner: J. Mater. Process. Tech. 71 (1997) 126. https://doi.org/10.1016/S09240136(97)00158-1

10 Z. Hamedon, K. Mori, and Y. Abe: J. Mater. Process. Tech. 214 (2014) 945. https://doi.org/10.1016/ j.jmatprotec.2013.11.016

11 G. C. Zhang, M. Ge, H. Tong, Y. Xu, and R. Du: Eng. Appl. Artif. Intel. 15 (2002) 97. https://oi.org/10.1016/ S0952-1976(02)00007-6

12 X. Li and A. M. Bassiuny: Int. J. Mach. Tool. Manu. 48 (2008) 576. https://doi.org/10.1016/ j.ijmachtools.2007.06.010

13 D. Y. Sari, T. L. Wu, and B. T. Lin: Int. J. Adv. Manuf. Tech. 88 (2017) 2275. https://doi.org/10.1007/s00170016-8956-y

14 H. Saiki, Y. Sakata, S. Satonaka, Y. Marumo, and Z. H. Zhan: Trans. Jpn. Soc. Mech. Eng. Ser. C 59 (1993) 1934 (in Japanese). https://doi.org/10.1299/kikaic.59.1934

15 S. Stancu-Niederkorn, U. Engel, and M. Geiger: J. Mater. Process. Tech. 45 (1994) 613. https://doi. org/10.1016/0924-0136(94)90407-3

16 H. Saiki, Y. Sakata, Y. Marumo, and Z. H. Zhan: Trans. Jpn. Soc. Mech. Eng. Ser. C 60 (1994) 3171 (in Japanese). https://doi.org/10.1299/kikaic.60.3171

17 N. Hagino, J. Endou, S. Katoh, and M. Ishihama: Steel Res. Int. Special Edition 2012 (2012) 319.

18 T. Nonaka, Y. Sakata, Y. Marumo, Y. Okinishi, H. Horinouchi, I. Ogawa, and S. Watanabe: Steel Res. Int. Special Edition (2012) 387.

19 R. Kakinoki, Y. Segawa, Y. Marumo, Y. Imamura, T, Nonaka, and Y. Sakata: Mater. Trans. 59 (2018) 799. https://doi.org/10.2320/matertrans.P-M2018807

20 Y. Segawa, T. Kuriyama, H. Harada, Y. Marumo, T. Lee, and Y. Imamura: Defect Diffus. Forum 382 (2018) 127. https://doi.org/10.4028/www.scientific.net/DDF.382.127

21 Y. Segawa, T. Kuriyama, Y. Marumo, T. Lee, Y. Imamura, T. Nonaka, and Y. Sakata: Int. J. Earth Sci. Eng. 10 (2017) 170. https://doi.org/10.21276/ijee.2017.10.0205

22 Y. Segawa, T. Kuriyama, Y. Marumo, T. Lee, Y. Imamura, T. Nonaka, and Y. Sakata: J. Jpn. Soc. Technol. Plast. 59 (2018) 47 (in Japanese). https://doi.org/10.9773/sosei.59.47

23 T. Ma, Y. Segawa, Y. Miyazaki, Y. Marumo, Y. Imamura, T. Nonaka, and Y. Sakata: Procedia Manuf. 15 (2018) 969. https://doi.org/10.1016/j.promfg.2018.07.398

24 Y. Segawa, D. Nishikubo, Y. Marumo, T. Nonaka, and Y. Sakata: Key Eng. Mater. 792 (2018) 185. https://doi. org/10.4028/www.scientific.net/KEM.792.185 